\title{
Lipid Peroxidation and Antioxidant Activities of the Aqueous Rhizome Extract of Rheum officinale Baillon
}

\author{
Eugene Chang ${ }^{1}$ and Choon Young Kim iD $^{2}$ \\ ${ }^{1}$ Department of Nutritional Science and Food Management, Ewha Womans University, Seoul 03760, Republic of Korea \\ ${ }^{2}$ Department of Food and Nutrition, Yeungnam University, Gyeongsan, Gyeongbuk 38541, Republic of Korea \\ Correspondence should be addressed to Choon Young Kim; cykim@yu.ac.kr
}

Received 22 January 2018; Accepted 14 May 2018; Published 9 July 2018

Academic Editor: Jorge Barros-Velázquez

Copyright (c) 2018 Eugene Chang and Choon Young Kim. This is an open access article distributed under the Creative Commons Attribution License, which permits unrestricted use, distribution, and reproduction in any medium, provided the original work is properly cited.

\begin{abstract}
Generation of reactive oxygen species (ROS) is associated with dysregulation of antioxidant defense mechanisms and incidence of human diseases. The specific aim of this study was to investigate the lipid oxidation and antioxidant activity of aqueous extract of Rheum officinale Baillon rhizome in order to evaluate its potential as a future novel natural antioxidant resource and a functional ingredient in food and pharmaceutical formations. Total phenolic and flavonoid contents of Rheum rhizome extract were dose dependently increased. Consistent with this, radical scavenging activities of Rheum rhizome extract as determined by 2,2diphenyl-1-picrylhydrazyl assay and 2,2'-azino-bis(3-ethylbenzothiazoline-6-sulfonic acid) radical scavenging activity were significantly elevated as the concentration increased. In addition, the treatment of aqueous Rheum rhizome extract significantly increased ferric reducing and copper chelating activities. According to results of thiobarbituric acid reactive substance analysis, Rheum rhizome extract significantly delayed lipid oxidation. Preincubation with Rheum rhizome extract significantly inhibited tert-butyl hydroperoxide- ( $t$-BHP-) induced ROS generation. Moreover, superoxide anion production was significantly lower in Rheum rhizome extract-treated RAW264.7 macrophage cells than $t$-BHP-incubated cells $(p<0.05)$. These findings suggest that Rheum officinale Baillon rhizome extract has a potential as an excellent natural antioxidant agent.
\end{abstract}

\section{Introduction}

Oxidative stress, which is an imbalance between the production of deleterious reactive oxygen species (ROS) and existing antioxidant defense system, plays a pivotal pathophysiological role in the development of liver disease, cancer, aging, autoimmune disorders, and cardiovascular and neurodegenerative diseases [1-5]. Overproduction of ROS such as hydroxyl radical $(\mathrm{OH} \cdot)$, superoxide radical $\left(\mathrm{O}_{2}^{-\cdot}\right)$, hydrogen peroxide $\left(\mathrm{H}_{2} \mathrm{O}_{2}\right)$, and nitric monoxide (NO.) readily attacks the polyunsaturated fatty acids in the plasma membrane, resulting in the oxidative degradation of lipids [6,7]. Consequently, lipid oxidation induces cellular and tissue damages through covalent binds, resulting in lipid peroxidation, DNA injury, inflammation, and subsequent cell death [8]. In addition, lipid oxidation in foods and food products lowers food quality, creating off-flavors and unhealthful compounds $[9,10]$. Therefore, it is of great interest to prevent
ROS production and lipid oxidation for the improvement of quality and nutrition of foods in the agriculture and food industry.

Rhubarb (Dahuang) is an herbaceous perennial in the Polygonaceae family and its root, stems, and leaves have been used as Asian traditional herbal medicine for treatment of constipation, jaundice, gastrointestinal hemorrhages, and ulcers. Recent accumulating evidence shows that several species of the Rheum genus such as Rheum emodi, Rheum undulatum L., Rhizoma Rhei, Rheum ribes, Rheum palmatum L., and Rheum rhaponticum have antiallergic, antibacterial, antioxidant, anticancer, antiangiogenesis, and anti-inflammation properties [11-20]. In relation to antioxidant capacity, anthraquinone derivates are considered to be one of the major biologically active constituents of aloeemodin, rhein, emodin, chrysophanol physcion, and danthron from the rhizomes of Rheum undulatum L. and Rheum palmatum L. [11, 12, 19, 21]. However, antioxidant 
capacity of Korean rhubarb, Rheum officinale Baillon, has never been investigated in spite of the rapid growing interest in using natural antioxidants and functional ingredients in foods and dietary supplements. Given the close association between food quality, oxidative stress, and health outcomes, the demand for applying natural antioxidants either in the form of raw extracts or their chemical constituents in foods has been fueled by a growing consumer preference for healthy foods. Therefore, the specific purpose of the study was to investigate the inhibitory effect of aqueous extract from Rheum officinale Baillon on lipid oxidation and oxidative stress.

\section{Materials and Methods}

2.1. Chemicals. Potassium persulfate was purchased from Junsei Chemical (Tokyo, Japan). Pyrocatechol violet (PV) and 2,2'-azino-bis(3-ethylbenzothiazoline-6-sulfonic acid) (ABTS) were purchased from TCI (Tokyo, Japan). Dimethyl sulfoxide (DMSO) was purchased from Amresco Inc. (Solon, OH, USA). Fetal bovine serum (FBS) was obtained from Gibco Invitrogen (Grand Island, NY, USA). Dulbecco's modified Eagle's medium (DMEM) and penicillin-streptomycin (PS) were obtained from Welgene (Gyeongsan, Gyeongsangbuk-do, Republic of Korea). Gum Arabic, 1,1,3,3-tetramethoxypropane (TEP), sodium dodecyl sulfate (SDS), phosphotungstic acid, and 2-thiobarbituric acid (TBA) were purchased from SigmaAldrich (St. Louis, MO, USA). Perilla oil was food grade and procured from a local supplier. All other chemicals, unless otherwise noted, were purchased from Sigma-Aldrich (St. Louis, MO, USA). All chemical reagents used in this study were of the highest purity commercially available.

2.2. Sample Preparation. Dried Rheum officinale Baillon rhizome was obtained from a local market (Gyeongsan, Gyeongsangbuk-do, Republic of Korea). Rhizome was pulverized using a grinder. Hot water extraction was carried out in a $5 \mathrm{~L}$ round-bottomed flask fitted with a cooling condenser at $121 \pm 1^{\circ} \mathrm{C}$ for $20 \mathrm{~min}$. The cooled extract was filtered through double layers of filter paper (No. 1, Whatman International Ltd., UK). The filtered extract was centrifuged at $11,000 \times \mathrm{g}$ for $20 \mathrm{~min}$, and this process was repeated three times. Supernatant was collected and stored at $4^{\circ} \mathrm{C}$ for further analysis.

2.3. Measurement of Total Phenolic Contents. Total phenol concentration of Rheum rhizome extract was determined using the Folin-Ciocalteu method [22]. In brief, $10 \mu \mathrm{L}$ of different concentrations of Rheum extract sample $(0.25,0.5$, $1.0,2.5$, and $5.0 \mathrm{mg} / \mathrm{mL}$ ) was added to a 96-well plate containing $10 \%$ Folin-Ciocalteu reagent $(20 \mu \mathrm{L})$. After $5 \mathrm{~min}, 80 \mu \mathrm{L}$ of $700 \mathrm{mM}$ sodium carbonate was added to the mixture and incubated for $1 \mathrm{~h}$ at room temperature. The absorbance was measured by a microplate spectrophotometer (Epoch, BioTek, Winooski, VT, USA) at a wavelength of $765 \mathrm{~nm}$. The concentration of phenolic compounds was calculated according to the following equation obtained from a standard curve of gallic acid. Total phenolic content was expressed as mg of gallic acid equivalent (GAE) per $\mathrm{mL}$ of aqueous Rheum rhizome extract.

2.4. Measurement of Total Flavonoid Contents. Total flavonoid content was measured by the aluminum chloride colorimetric method. $25 \mu \mathrm{L}$ of Rheum rhizome extract in the final concentration range of $0.25-5.0 \mathrm{mg} / \mathrm{mL}$ was added to a 96-well plate containing $125 \mu \mathrm{L}$ of distilled water followed by the addition of $10 \mu \mathrm{L}$ of $5 \%$ sodium nitrite solution. After $6 \mathrm{~min}$, the reaction was carried out by addition of $15 \mu \mathrm{L}$ of $10 \%(\mathrm{w} / \mathrm{v})$ aluminum chloride. After $5 \mathrm{~min}, 50 \mu \mathrm{L}$ of $1 \mathrm{mM}$ sodium hydroxide and $275 \mu \mathrm{L}$ of distilled water were added and mixed thoroughly. The absorbance was measured at a wavelength of $510 \mathrm{~nm}$. The concentration of total flavonoid compounds was determined as compared to a standard curve of catechin as earlier described and expressed as mg of catechin per $\mathrm{mL}$ of aqueous Rheum rhizome extract.

2.5. DPPH Radical Scavenging Activity Assay. Free radical scavenging activity of Rheum extract was measured by DPPH assay. DPPH stock solution was freshly prepared in methanol at a concentration of $0.02 \%$. An aliquot of $50 \mu \mathrm{L}$ sample solution at a wide dose range from 0.25 to $5.0 \mathrm{mg} / \mathrm{mL}$ was mixed with $100 \mu \mathrm{L}$ of DPPH reagent solution. After $30 \mathrm{~min}$ of incubation at room temperature in the dark, the absorbance of the mixture was measured at $510 \mathrm{~nm}$ against a blank. Scavenging activity was expressed as mg of ascorbic acid (AA) per $\mathrm{mL}$ of aqueous Rheum rhizome extract.

$$
\begin{aligned}
& \text { DPPH radical scavenging activity }(\%)= \\
& {\left[1-\left\{\frac{\Delta \mathrm{ABS}(\text { sample }- \text { blank })}{\mathrm{ABS}(\text { control })}\right\} \times 100\right] .}
\end{aligned}
$$

2.6. ABTS Radical Scavenging Activity Assay. As described previously [23], ABTS stock solution (7.4 mM) was added to $2.6 \mathrm{mM}$ potassium persulfate solution in equal quantities and kept for $16 \mathrm{~h}$ at room temperature in the dark to yield a dark colored solution containing ABTS radical cation. Before use, ABTS radical cation was diluted to an initial absorbance of about $0.7 \pm 0.02$ at $734 \mathrm{~nm}$. Free radical scavenging activity was determined by the addition of $10 \mu \mathrm{L}$ of Rheum rhizome extract from 5 different final concentrations $(0.25,0.5,1.0,2.5$, and $5.0 \mathrm{mg} / \mathrm{mL}$ ) to $290 \mu \mathrm{L}$ of ABTS working solution. After $6 \mathrm{~min}$, the absorbance was determined at $734 \mathrm{~nm}$. ABST radical scavenging activity was expressed as $\mathrm{mg}$ of trolox equivalent (TE) per $\mathrm{mL}$ of aqueous Rheum rhizome extract.

ABTS radical scavenging activity $(\%)=$

$$
\left[1-\left\{\frac{\Delta \mathrm{ABS}(\text { sample }- \text { blank })}{\mathrm{ABS}(\text { control })}\right\} \times 100\right] \text {. }
$$

2.7. Ferric Reducing Antioxidant Power (FRAP) Assay. Reducing power was measured based on conversion of $\mathrm{Fe}(\mathrm{III})$ to $\mathrm{Fe}$ (II) using the method described by Benzie and Strain [24]. Briefly, FRAP working reagent was prepared by 
addition of $300 \mathrm{mM}$ acetate buffer ( $\mathrm{pH} 3.6$ ), $10 \mathrm{mM}$ 2,4,6tripyridyl-s-triazine (TPTZ) solution in $40 \mathrm{mM} \mathrm{HCl}$, and $20 \mathrm{mM}$ ferric chloride $\left(\mathrm{FeSO}_{4} \cdot 6 \mathrm{H}_{2} \mathrm{O}\right)$ solution at a $10: 1: 1$ ratio. A wide dose range of $10 \mu \mathrm{L}$ Rheum rhizome aqueous extract $(0.25,0.5,1.0,2.5$, and $5.0 \mathrm{mg} / \mathrm{mL})$ was mixed with $10 \mu \mathrm{L}$ of distilled water, followed by the addition of prewarmed FRAP working reagent $(100 \mu \mathrm{L})$. Optical density of the mixture was measured at a wavelength of $593 \mathrm{~nm}$. Reducing power was described as the use of ferrous sulfate $\left(\mathrm{FeSO}_{4} \cdot 7 \mathrm{H}_{2} \mathrm{O}\right)$.

2.8. Determination of Copper Chelating Activity. Cupric reducing antioxidant capacity of Rheum extract was determined according to the method of Megías [25]. In each well of a 96-well plate, $30 \mu \mathrm{L}$ hot water extract sample which final concentration was different from 0.25 to $5.0 \mathrm{mg} / \mathrm{mL}$ was mixed with $6 \mu \mathrm{L}$ of $4 \mathrm{mM} \mathrm{PV}, 290 \mu \mathrm{L}$ of $50 \mathrm{mM}$ sodium acetate buffer ( $\mathrm{pH} 6.0$ ), and $10 \mu \mathrm{L}$ of $2 \mathrm{mM}$ copper sulfate. In order to measure copper chelating activity, absorbance was determined at $632 \mathrm{~nm}$ according to the following equation:

$$
\begin{array}{r}
\text { Copper chelating activity }(\%)= \\
{\left[1-\left\{\frac{\Delta \mathrm{ABS}(\text { sample }- \text { blank })}{\mathrm{ABS}(\text { control })}\right\} \times 100\right] .}
\end{array}
$$

2.9. Measurement of Lipid Peroxidation. Oil emulsion was prepared by mixing raw perilla oil and rhubarb aqueous extract at the ratio of 3 to 1 . Then, raw perilla oil emulsions were mixed with $10 \%$ gum arabic as an emulsifier and homogenized for $16 \mathrm{~min}$ by homogenizer (AM-8, Nissei, Japan). Lipid oxidation of the oil emulsion was induced at $30^{\circ} \mathrm{C}$ or $70^{\circ} \mathrm{C}$ using incubator (JISICO, Korea) and water bath (Shaking Water Bath, JEIO Tech, Korea), respectively. Heated raw perilla oil emulsions were collected at 0,7 , and 10 days of incubation. The lipid oxidation of raw perilla oil was analyzed by thiobarbituric acid reactive substance (TBARS) assay [26]. In brief, $10 \mu \mathrm{L}$ of samples (rhubarb) at three different concentrations of $0,0.25$, and $5 \mathrm{mg} / \mathrm{mL}$ or standard solution (1,1,3,3-tetramethoxypropane, TEP) and $40 \mu \mathrm{L}$ of $20 \mathrm{mM}$ phosphate buffer ( $\mathrm{pH} 7.0$ ) were added to an Eppendorf tube on ice. In each tube, $50 \mu \mathrm{L}$ of $3 \%$ sodium dodecyl sulfate (SDS), $200 \mu \mathrm{L}$ of $0.1 \mathrm{~N} \mathrm{HCl}, 30 \mu \mathrm{L}$ of $10 \%$ phosphotungstic acid, and $100 \mu \mathrm{L}$ of $0.7 \%$ of 2 -thiobarbituric acid (TBA) were added. The tubes were firmly closed and boiled at $100^{\circ} \mathrm{C}$ for $30 \mathrm{~min}$ in water bath. The reaction mixture was mixed with $400 \mu \mathrm{L}$ of $n$-butanol and then centrifuged at $3000 \mathrm{rpm}$ for $10 \mathrm{~min}$. Supernatants were collected and loaded in a 96-well plate. Fluorescence intensity was read at the excitation/emission wavelengths of $515 \mathrm{~nm} / 555 \mathrm{~nm}$ using microplate reader (VICTOR Multilabel Plate Reader, PerkinElmer, Korea).

\subsection{In Vitro RAW264.7 Macrophage Study}

2.10.1. Measurement of Cell Viability. RAW264.7 macrophage cells were cultured at $37^{\circ} \mathrm{C}$ and $5 \% \mathrm{CO}_{2}$ in DMEM with $10 \% \mathrm{FBS}$ and $1 \%$ PS. Cell viability was determined by a modified 3-(4,5-dimethylthiazol-2-yl)-2,5-diphenyltetrazolium bromide (MTT) assay [27]. RAW264.7 cells were seeded on a 24-well plate at a density of $1 \times 10^{5}$ cells/well and cultured overnight. After $24 \mathrm{~h}$ treatment of Rheum extract with different concentrations $(0,0.1,0.5$, and $1 \mathrm{mg} / \mathrm{mL})$, RAW264.7 cells were incubated $0.5 \mathrm{mM}$ tert-butyl hydroperoxide $(t-\mathrm{BHP})$ for $1 \mathrm{~h}$. Further incubation with MTT dye solution $(0.5 \mathrm{mg} / \mathrm{mL}$ MTT solution and medium at a ratio of $1: 5)$ was executed for $1 \mathrm{~h}$. After dissolving purple formazan into DMSO, the absorbance of the product was measured at $540 \mathrm{~nm}$. The percentage of cell viability was calculated by the following equation:

$$
\text { Cell viability }(\% \text { of control })=\frac{\mathrm{OD}_{\text {sample-blank }}}{\mathrm{OD}_{\text {Control-blank }}} \times 100 \text {. }
$$

2.10.2. Determination of Cell Toxicity. Effect of aqueous Rheum rhizome extract on cell toxicity was measured by neutral red assay [28]. RAW264.7 cells $\left(1 \times 10^{5}\right.$ cells/well in a 24-well plate) were treated with different concentrations of aqueous Rheum extract $(0,0.1,0.5$, and $1 \mathrm{mg} / \mathrm{mL})$ for $24 \mathrm{~h}$, followed by treatment of $0.5 \mathrm{mM} t$-BHP for an additional $1 \mathrm{~h}$. Culture medium was changed to $0.004 \%$ neutral red solution dissolved in medium and incubated for $3 \mathrm{~h}$. Lysis buffer containing distilled water, ethanol, and acetic acid at a ratio of $50: 49: 1$ was added to each well and the plate was rocking for $15 \mathrm{~min}$. The optical density at $540 \mathrm{~nm}$ was measured.

2.10.3. Measurement of Intracellular Reactive Oxygen Species (ROS) Levels. The level of intracellular ROS was determined using $2^{\prime}, 7^{\prime}$-dichlorofluorescin diacetate (DCFH-DA) [29]. RAW264.7 cells were planted on a 96-well plate at a density of $5 \times 10^{4}$ cells/well and incubated at $37^{\circ} \mathrm{C}$ and $5 \% \mathrm{CO}_{2}$ for $24 \mathrm{~h}$. After $24 \mathrm{~h}$ of treatment of Rheum extract (0, 0.1, 0.5, and $1 \mathrm{mg} / \mathrm{mL}$ ), the medium was changed to PBS containing $120 \mu \mathrm{M}$ DCFH-DA with or without $0.5 \mathrm{mM} t$-BHP and incubated for $60 \mathrm{~min}$ at $37^{\circ} \mathrm{C}$. The absorbance was determined at $488 \mathrm{~nm}$ excitation and $525 \mathrm{~nm}$ emission by using a fluorescence plate reader (VICTOR X3, PerkinElmer, Turku, Singapore).

2.10.4. Measurements of Superoxide Anion Production. Preincubated RAW264.7 cells with Rheum extract (0, 0.1, 0.5 , and $1 \mathrm{mg} / \mathrm{mL}$ ) for $24 \mathrm{~h}$ were incubated with or without $0.5 \mathrm{mM} t$-BHP for $1 \mathrm{~h}$. NBT solution $(0.5 \mathrm{mg} / \mathrm{mL} \mathrm{NBT}$ solution and medium at a ratio of $1: 5$ ) was added and further incubated at $37^{\circ} \mathrm{C}$ and $5 \% \mathrm{CO}_{2}$ for $7 \mathrm{~h}$. Medium was removed, and lysis buffer including DMSO and $2 \mathrm{M}$ potassium hydroxide at a ratio of $1: 1$ was added. The absorbance was measured at $570 \mathrm{~nm}$.

2.11. Statistical Analysis. The data are presented as the mean \pm standard deviation (SD) of at least three independent triplicate experiments. Data were analyzed by the ANOVA procedure using the Statistical Analysis System (SAS 9.4) software. Differences among groups were determined using Bonferroni procedure at the $5 \%$ level. 


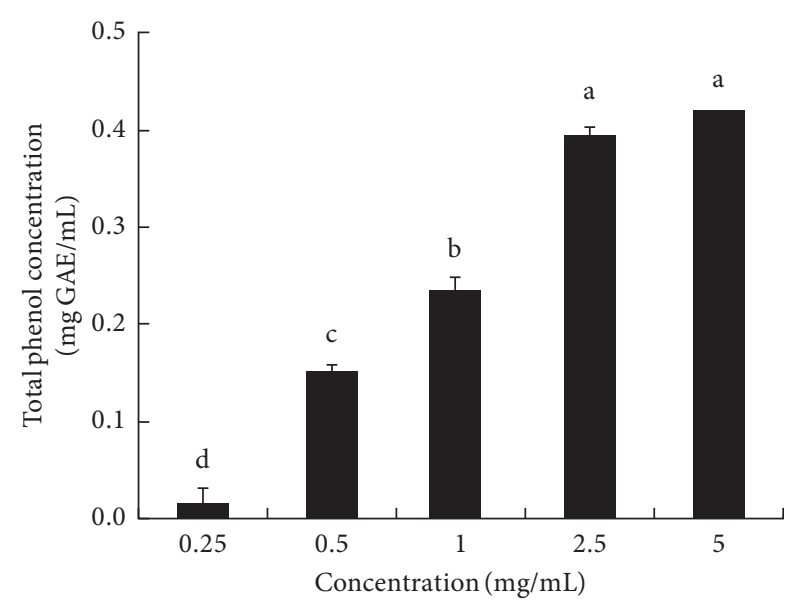

(a)

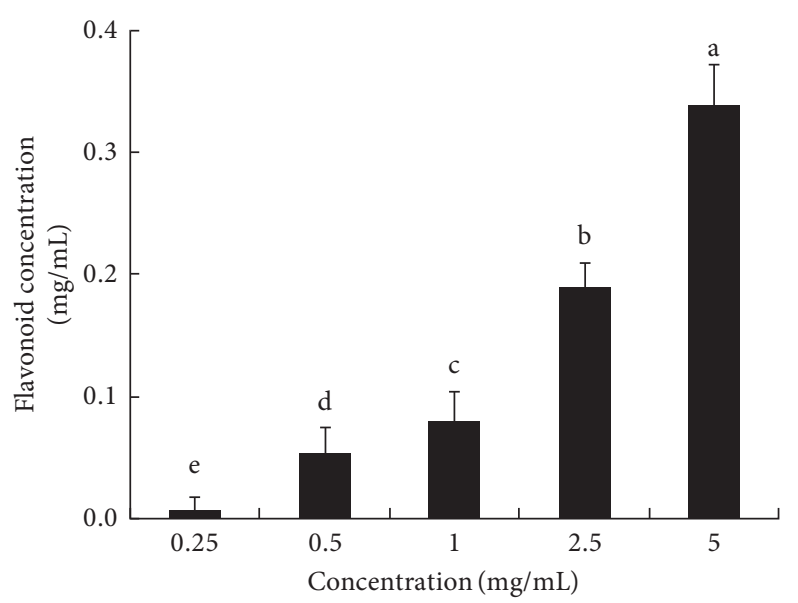

(b)

Figure 1: Effect of aqueous Rheum rhizome extracts on total phenol (a) and flavonoid (b) contents. The concentrations of total phenolic compounds and flavonoids are calculated according to standard curves of gallic acid and catechin and expressed as milligrams of gallic acid equivalent (GAE) and catechin per milliliter of aqueous Rheum rhizome extract. Values are expressed as the mean \pm standard deviation (SD) $(n=9)$. Bars with different letters indicate significant differences $(p<0.05)$.

TABLE 1: Radical scavenging and metal chelating activities of aqueous Rheum extracts.

\begin{tabular}{lcccc}
\hline $\begin{array}{l}\text { Concentration of Rheum } \\
\text { extract }(\mathrm{mg} / \mathrm{mL})\end{array}$ & $\begin{array}{c}\text { DPPH } \\
(\mathrm{mg} \mathrm{AA} / \mathrm{mL})\end{array}$ & $\begin{array}{c}\text { ABTS } \\
(\mathrm{mg} \mathrm{TE} / \mathrm{mL})\end{array}$ & $\begin{array}{c}\text { FRAP } \\
\left(\mathrm{mM} \mathrm{Fe}^{2+} / \mathrm{mL}\right)\end{array}$ & $\begin{array}{c}\text { Copper chelating } \\
(\% \text { of control) }\end{array}$ \\
\hline 0.25 & $0.02 \pm 0.01^{\mathrm{a}}$ & $0.38 \pm 0.01^{\mathrm{d}}$ & $0.02 \pm 0.02^{\mathrm{c}}$ & $2.68 \pm 4.86^{\mathrm{a}}$ \\
0.50 & $0.05 \pm 0.01^{\mathrm{b}}$ & $0.76 \pm 0.02^{\mathrm{c}}$ & $0.08 \pm 0.03^{\mathrm{bc}}$ & $8.80 \pm 4.93^{\mathrm{ab}}$ \\
1.00 & $0.07 \pm 0.01^{\mathrm{c}}$ & $0.88 \pm 0.01^{\mathrm{b}}$ & $0.13 \pm 0.04^{\mathrm{b}}$ & $13.98 \pm 3.85^{\mathrm{b}}$ \\
2.50 & $0.11 \pm 0.02^{\mathrm{d}}$ & $0.94 \pm 0.00^{\mathrm{a}}$ & $0.21 \pm 0.01^{\mathrm{a}}$ & $23.61 \pm 5.72^{\mathrm{c}}$ \\
5.00 & $0.13 \pm 0.02^{\mathrm{e}}$ & $0.94 \pm 0.00^{\mathrm{a}}$ & $0.33 \pm 0.09^{\mathrm{a}}$ & $45.01 \pm 2.88^{\mathrm{d}}$ \\
\hline
\end{tabular}

Values are expressed as the mean \pm standard deviation (SD) from at least three experiments $(n=9)$. Different letters indicate a significant difference among groups according to Bonferroni procedure $(p<0.05)$. AA, ascorbic acid; ABTS, 2,2' -azino-bis(3-ethylbenzothiazoline-6-sulfonic acid; DPPH, 2,2-diphenyl-1picrylhydrazyl); FRAP, ferric reducing antioxidant power; TE, Trolox equivalent.

\section{Results and Discussion}

3.1. Total Phenolic and Flavonoid Contents. Polyphenolic compounds including flavonoids are known as powerful antioxidants due to their hydroxyl groups and radical scavenging activities. These compounds may contribute directly to antioxidant capacity, thus having protective functions against oxidative damage and health benefits [30-33]. In order to investigate antioxidant activity of Rheum aqueous extract, we first examined concentrations of total phenols and flavonoids. As shown in Figure 1(a), total phenolic contents of rhizome extract significantly increased in a dose-dependent manner with a significant increase at $0.5 \mathrm{mg} / \mathrm{mL}$. Total flavonoid concentration reached a maximum at $5 \mathrm{mg} / \mathrm{mL}$, about 30 folds higher than $0.25 \mathrm{mg} / \mathrm{mL}$ (Figure $1(\mathrm{~b})$ ). These findings suggest that flavonoids and phenols may be important components of Rheum officinale Baillon, and its radical scavenging activity could be attributed to the presence of these constituents.

\subsection{Radical Scavenging and Metal Chelating Activities.} Excess generation of free radicals or ROS causes oxidative stress and disease [1-5]. Increased use of naturally occurring antioxidants is considerably regarded as an effective and safe way to prevent ROS-induced diseases. Therefore, we determined the antioxidant effect of Rheum extract based on radical scavenging. The electron donation ability of rhizome extract from Rheum was determined by DPPH purple-colored solution bleaching assay. Aqueous Rheum extract significantly increased the degree of color change in a dose-dependent manner, indicating significant free radical scavenging activity (Table 1). In addition, the extent of decolorization measured as the percentage inhibition of ABTS radical cation was assessed after addition of Rheum rhizome extract (Table 1). Aqueous extract of Rheum rhizome significantly increased both DPPH and ABTS radical scavenging activities in a dose-dependent manner from a concentration of 0.25 to $5 \mathrm{mg} / \mathrm{mL}$, indicating strong free radical scavenging activity.

Copper(I) and iron(II) are regarded as catalysts for the generation of highly reactive hydroxyl radicals, which cause cell or tissue damages, and consequently diseases [6, 7]. Therefore, copper chelating capacity and ferric reducing activity are important markers for antioxidant activity of natural resources and functional ingredients [34-36]. As shown in Table 1, both ferric reducing capacity and copper chelating activity were significantly increased by Rheum extract in a dose-dependent manner, in ranges of $0.02-$ $0.32 \mathrm{mM}$ ferric levels and 3-35\% copper chelating compared 
TABLE 2: Inhibitory effect of rhubarb aqueous extract on lipid oxidation over storage time at $30^{\circ} \mathrm{C}$ and $70^{\circ} \mathrm{C}$.

\begin{tabular}{lcccc}
\hline \multirow{2}{*}{ Storage time (days) } & Storage temperature $\left({ }^{\circ} \mathrm{C}\right)$ & \multicolumn{3}{c}{ Concentration of rhubarb $(\mathrm{mg} / \mathrm{mL})$} \\
\hline 0 & - & $50 \pm 7.44^{\mathrm{Ad}}$ & $47 \pm 4.08^{\mathrm{Bc}}$ & $45 \pm 1.95^{\mathrm{Bd}}$ \\
7 & 30 & $125 \pm 3.32^{\mathrm{Ac}}$ & $77 \pm 4.49^{\mathrm{Bc}}$ & $74 \pm 3.17^{\mathrm{Bc}}$ \\
& 70 & $199 \pm 21.92^{\mathrm{Ab}}$ & $192 \pm 11.04^{\mathrm{Aa}}$ & $136 \pm 7.81^{\mathrm{Bab}}$ \\
10 & 30 & $237 \pm 0.92^{\mathrm{Aab}}$ & $130 \pm 4.30^{\mathrm{Bb}}$ & $119 \pm 7.14^{\mathrm{Bb}}$ \\
& 70 & $277 \pm 8.37^{\mathrm{Aa}}$ & $232 \pm 21.86^{\mathrm{Aa}}$ & $161 \pm 9.98^{\mathrm{Ba}}$ \\
\hline
\end{tabular}

Data are expressed as the mean \pm standard deviation (SD) from at least three experiments $(n=9)$. Different letters (A, B, C) within same row indicate a significant difference groups with the same storage time and temperature $(p<0.05)$. Small letters $(\mathrm{a}-\mathrm{e})$ demonstrate significant difference at a given concentration of rhubarb aqueous extract $(p<0.05)$.

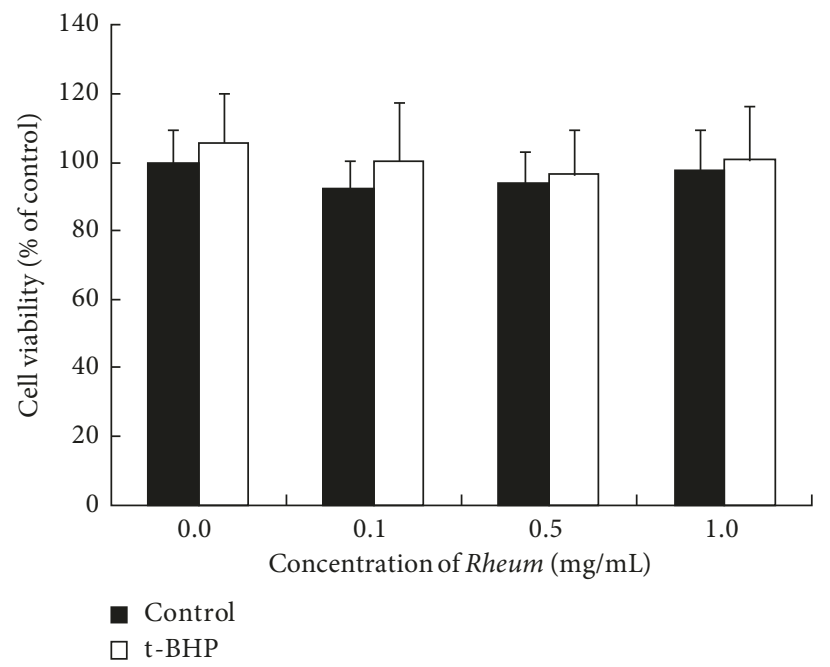

(a)

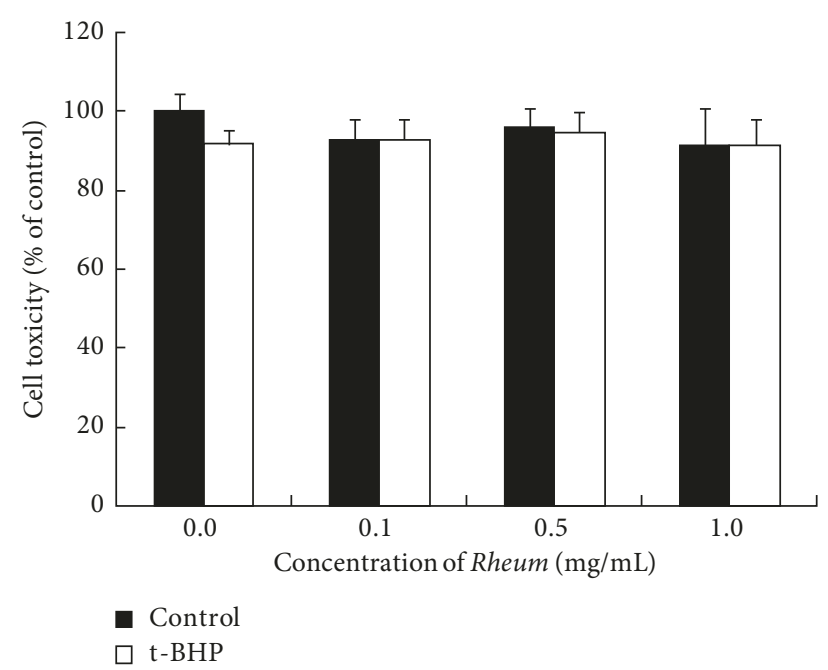

(b)

FIGURE 2: Effects of Rheum rhizome extract on cell viability (a) and cell toxicity (b) in $0.5 \mathrm{mM}$ tert-butyl hydroperoxide- ( $t$-BHP-) induced RAW264.7 macrophages. Each value represents the mean \pm standard deviation (SD) from at least three experiments $(n=9)$. Bars with different letters differ among aqueous Rheum rhizome extract treatment groups $(p<0.05)$.

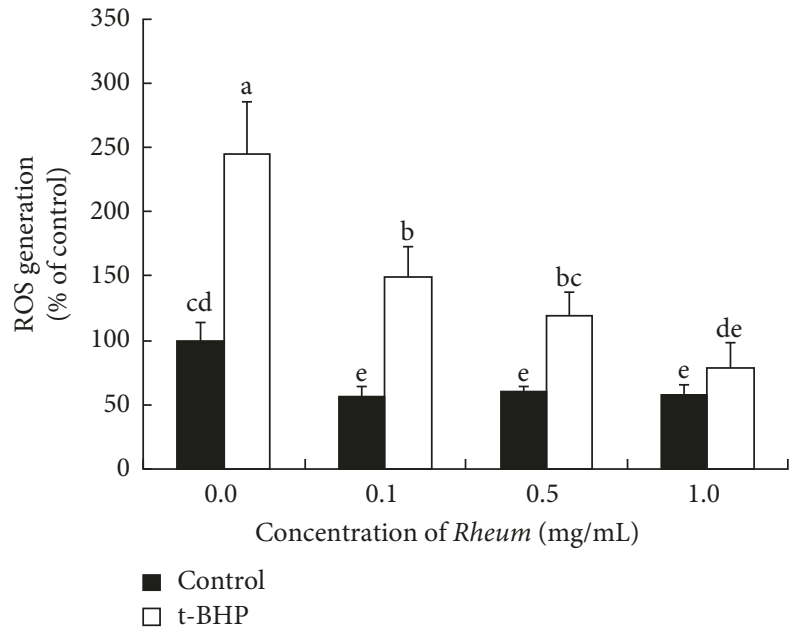

(a)

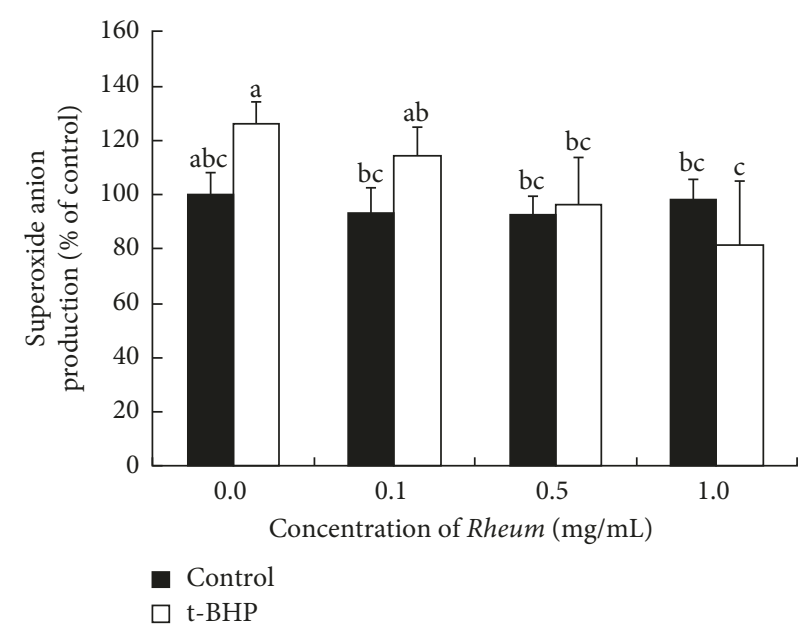

(b)

FIGURE 3: Effects of Rheum rhizome extract on production of intracellular reactive oxygen species (a) and superoxide anion (b) in $0.5 \mathrm{mM}$ tert-butyl hydroperoxide- ( $t$-BHP-) induced RAW264.7 macrophages. The value of each bar represents the mean \pm standard deviation (SD) $(n=9)$. Means sharing the same letter are not significantly different at the $5 \%$ level. 
to control, respectively. These results demonstrated that Rheum rhizome extract has antioxidant capacity mediated by ferric reducing and copper chelating activities.

3.3. Lipid Oxidation. Increased oxidation process in the foods contributes to food quality deterioration by increasing oxidative rancidity and deleterious food product as well as losing color and nutrient value $[9,10]$. Thereby, the ways in which antioxidants inhibit oxidation of food and increase the antioxidant efficacy have attracted much attention. In the present study, inhibitory effect of aqueous Rheum extract on lipid oxidation was measured using thiobarbituric acid reactive substances assay. Malondialdehyde, the end product of lipid oxidation, was significantly generated as storage time and temperature were increased (Table 2). Even though lipid peroxidation in oil emulsion mixture was significantly increased according to storage temperature and times, treatment of aqueous extract of Rheum rhizome significantly suppressed malondialdehyde levels in the raw perilla oil emulsions in a dose-dependent manner. This result supported that aqueous extract of Rheum officinale Baillon inhibits lipid oxidation.

3.4. Antioxidant Properties of Rheum Aqueous Extract in t-BHP-Treated RAW264.7 Murine Macrophages. Antioxidant effect of Rheum officinale Baillon was determined in in vitro cell culture model, $t$-BHP treated RAW264.7 macrophage cells. First, we measured the cytotoxic effect of Rheum officinale Baillon rhizome extract. After $24 \mathrm{~h}$ exposure to 0.1, 0.5 , and $1 \mathrm{mg} / \mathrm{mL}$ of Rheum extract, viabilities of RAW264.7 cells were not statistically different from control, regardless of $t$-BHP treatment (Figure 2(a)). In addition, cell toxicity was not altered by either Rheum extract or $t$-BHP treatment (Figure 2(b)). These results indicate that Rheum extract at any concentration ranging from 0.1 to $1 \mathrm{mg} / \mathrm{mL}$ had no significant cytotoxicity on RAW264.7 cell viability.

As an indicator of oxidative stress, increased production of ROS promotes the pathogenesis of multiple diseases [1-5]. In order to evaluate the effect of Rheum extract on oxidative process, measurement of ROS and superoxide anion production were carried out in $t$-BHP-treated RAW264.7 cells. In the presence of Rheum extract, $t$-BHP-induced ROS (Figure $3(\mathrm{a})$ ) and superoxide anion production (Figure 3(b)) were significantly diminished in a dose-dependent manner, compared to $t$-BHP only-treated cells.

\section{Conclusions}

In the present study, analysis of radical scavenging abilities, metal chelating activities, and total phenolic and flavonoid contents showed that aqueous extract from Rheum officinale Baillon rhizome could be a potent source of natural antioxidants. In addition, Rheum aqueous extract significantly inhibited lipid oxidation in a dose-dependent manner. To the best of our knowledge, this is the first study to suggest that aqueous extract of Korean Rhubarb (Rheum officinale Baillon) rhizome may be useful as a natural antioxidant due to its antioxidant capacities to prevent ROS generation and delay oxidant degradation of lipids.

\section{Data Availability}

The data used to support the findings of this study are available from the corresponding author upon request.

\section{Conflicts of Interest}

The authors declare no conflicts of interest.

\section{Acknowledgments}

The authors greatly appreciate the technical assistance from Darae Lee and Naeun Jeon, Yeungnam University. This work was supported by the 2014 Yeungnam University Research Grant.

\section{References}

[1] R. L. Auten and J. M. Davis, "Oxygen toxicity and reactive oxygen species: the devil is in the details," Pediatric Research, vol. 66, no. 2, pp. 121-127, 2009.

[2] A. H. Bhat, K. B. Dar, S. Anees et al., "Oxidative stress, mitochondrial dysfunction and neurodegenerative diseases; a mechanistic insight," Biomedicine and Pharmacotherapy, vol. 74, pp. 101-110, 2015.

[3] J. S. Bhatti, G. K. Bhatti, and P. H. Reddy, "Mitochondrial dysfunction and oxidative stress in metabolic disorders-a step towards mitochondria based therapeutic strategies," Biochimica et Biophysica Acta (BBA)-Molecular Basis of Disease, vol. 1863, no. 5, pp. 1066-1077, 2017.

[4] L. A. Pham-Huy, H. He, and C. Pham-Huy, "Free radicals, antioxidants in disease and health," International Journal of Biomedical Science, vol. 4, no. 2, pp. 89-96, 2008.

[5] B. P. Yu, "Cellular defenses against damage from reactive oxygen species," Physiological Reviews, vol. 74, no. 1, pp. 139-162, 1994.

[6] M. Ott, V. Gogvadze, S. Orrenius, and B. Zhivotovsky, "Mitochondria, oxidative stress and cell death," Apoptosis, vol. 12, no. 5, pp. 913-922, 2007.

[7] G. Stark, "Functional consequences of oxidative membrane damage," Journal of Membrane Biology, vol. 205, no. 1, pp. 1-16, 2005.

[8] E. Birben, U. M. Sahiner, C. Sackesen, S. Erzurum, and O. Kalayci, "Oxidative stress and antioxidant defense," World Allergy Organization Journal, vol. 5, no. 1, pp. 9-19, 2012.

[9] A. J. St. Angelo, J. Vercellotti, T. Jacks, and M. Legendre, "Lipid oxidation on foods," Critical Reviews in Food Science and Nutrition, vol. 36, no. 3, pp. 175-224, 1996.

[10] I. Gülçin, "Antioxidant activity of food constituents: an overview," Archives of Toxicology, vol. 86, no. 3, pp. 345-391, 2012.

[11] Z. H. He, R. Zhou, M. F. He et al., "Anti-angiogenic effect and mechanism of rhein from Rhizoma Rhei," Phytomedicine, vol. 18, no. 6, pp. 470-478, 2011.

[12] B. Hu, H. Zhang, X. Meng, F. Wang, and P. Wang, "Aloeemodin from rhubarb (Rheum rhabarbarum) inhibits lipopolysaccharide-induced inflammatory responses in RAW264.7 macrophages," Journal of Ethnopharmacology, vol. 153, no. 3, pp. 846-853, 2014.

[13] L. Lu and H. Yin, "Effects of Dahuang (Rhubarb) retention enema on leukocyte interleukin-6, high sensitive $C$ reactive protein and endotoxin in patients with acute pancreatitis," Medicinal Plants, vol. 9, pp. 60-62, 2018. 
[14] H. Matsuda, N. Tomohiro, K. Hiraba et al., "Study on AntiOketsu Activity of Rhubarb II. Anti-allergic effects of stilbene components from Rhei undulati Rhizoma (dried rhizome of Rheum undulatum cultivated in Korea)," Biological and Pharmaceutical Bulletin, vol. 24, no. 3, pp. 264-267, 2001 a.

[15] H. Matsuda, T. Morikawa, I. Toguchida, J. Y. Park, S. Harima, and M. Yoshikawa, "Antioxidant constituents from rhubarb: structural requirements of stilbenes for the activity and structures of two new anthraquinone glucosides," Bioorganic and Medicinal Chemistry, vol. 9, no. 1, pp. 41-50, $2001 \mathrm{~b}$.

[16] T. M. Ngoc, T. M. Hung, P. T. Thuong et al., "Inhibition of human low density lipoprotein and high density lipoprotein oxidation by oligostilbenes from rhubarb," Biological and Pharmaceutical Bulletin, vol. 31, no. 9, pp. 1809-1812, 2008.

[17] M. Öztürk, F. Aydoğmuş-Öztürk, M. E. Duru, and G. Topçu, "Antioxidant activity of stem and root extracts of Rhubarb (Rheum ribes): An edible medicinal plant," Food Chemistry, vol. 103, no. 2, pp. 623-630, 2007.

[18] P. Raudsepp, D. Anton, M. Roasto et al., "The antioxidative and antimicrobial properties of the blue honeysuckle (Lonicera caerulea L.), Siberian rhubarb (Rheum rhaponticum L.) and some other plants, compared to ascorbic acid and sodium nitrite," Food Control, vol. 31, no. 1, pp. 129-135, 2013.

[19] C. S. Shia, S. H. Juang, S. Y. Tsai et al., "Metabolism and pharmacokinetics of anthraquinones in Rheum palmatum in rats and ex vivo antioxidant activity," Planta Medica, vol. 75, no. 13, pp. 1386-1392, 2009.

[20] J. P. Silveira, L. N. Seito, S. Eberlin et al., "Photoprotective and antioxidant effects of Rhubarb: inhibitory action on tyrosinase and tyrosine kinase activities and TNF-alpha, IL-1alpha and alpha-MSH production in human melanocytes," BMC Complementary and Alternative Medicine, vol. 13, no. 1, p. 49, 2013.

[21] T. Venkatesan, M. J. Jeong, Y. W. Choi, E. J. Park, S. K. El-Desouky, and Y. K. Kim, "Deoxyrhapontigenin, a natural stilbene derivative isolated from Rheum undulatum L. induces endoplasmic reticulum stress-mediated apoptosis in human breast cancer cells," Integrative Cancer Therapies, vol. 15, no. 4, pp. NP44-NP52, 2016.

[22] V. L. Singleton, R. Orthofer, and R. M. Lamuela-Raventos, "Analysis of total phenols and other oxidation substrates and antioxidants by means of folin-ciocalteu reagent," Methods in Enzymology, vol. 299, pp. 152-178, 1999.

[23] R. Re, N. Pellegrini, A. Proteggente, A. Pannala, M. Yang, and C. Rice-Evans, "Antioxidant activity applying an improved ABTS radical cation decolorization assay," Free Radical Biology and Medicine, vol. 26, no. 9-10, pp. 1231-1237, 1999.

[24] I. F. Benzie and J. J. Strain, "The ferric reducing ability of plasma (FRAP) as a measure of "antioxidant power": the FRAP assay," Analytical Biochemistry, vol. 239, no. 1, pp. 70-76, 1996.

[25] C. Megías, E. Pastor-Cavada, C. Torres-Fuentes et al., "Chelating, antioxidant and antiproliferative activity of Vicia sativa polyphenol extracts," European Food Research and Technology, vol. 230, no. 2, pp. 353-359, 2009.

[26] P. Ke, E. Cervantes, and C. Robles-Martinez, "Determination of thiobarbituric acid reactive substances (TBARS) in fish tissue by an improved distillation-spectrophotometric method," Journal of the Science of Food and Agriculture, vol. 35, no. 11, pp. 1248-1254, 1984.

[27] T. Mosmann, "Rapid colorimetric assay for cellular growth and survival: application to proliferation and cytotoxicity assays," Journal of Immunological Methods, vol. 65, no. 1-2, pp. 55-63, 1983.
[28] E. Borenfreund and J. A. Puerner, "Toxicity determined in vitro by morphological alterations and neutral red absorption," Toxicology Letters, vol. 24, no. 2-3, pp. 119-124, 1985.

[29] K. Nishio, M. Horie, Y. Akazawa et al., "Attenuation of lipopolysaccharide (LPS)-induced cytotoxicity by tocopherols and tocotrienols," Redox Biology, vol. 1, no. 1, pp. 97-103, 2013.

[30] L. Bravo, "Polyphenols: chemistry, dietary sources, metabolism, and nutritional significance," Nutrition Reviews, vol. 56, no. 11, pp. 317-333, 1998.

[31] Y. Cai, Q. Luo, M. Sun, and H. Corke, "Antioxidant activity and phenolic compounds of 112 traditional Chinese medicinal plants associated with anticancer," Life Sciences, vol. 74, no. 17 , pp. 2157-2184, 2004.

[32] G. Di Carlo, N. Mascolo, A. A. Izzo, and F. Capasso, "Flavonoids: old and new aspects of a class of natural therapeutic drugs," Life Sciences, vol. 65, no. 4, pp. 337-353, 1999.

[33] F Shahidi and P Ambigaipalan, "Phenolics and polyphenolics in foods, beverages and spices: antioxidant activity and health effects-a review," Journal of Functional Foods, vol. 18, pp. 820-897, 2015.

[34] M. S. Brewer, "Natural antioxidants: sources, compounds, mechanisms of action, and potential applications," Comprehensive Reviews in Food Science and Food Safety, vol. 10, no. 4, pp. 221-247, 2011.

[35] B. Ou, D. Huang, M. Hampsch-Woodill, J. A. Flanagan, and E. K. Deemer, "Analysis of antioxidant activities of common vegetables employing oxygen radical absorbance capacity (ORAC) and ferric reducing antioxidant power (FRAP) assays: a comparative study," Journal of Agricultural and Food Chemistry, vol. 50, no. 11, pp. 3122-3128, 2002.

[36] R. Apak, K. Guclu, B. Demirata et al., "Comparative evaluation of various total antioxidant capacity assays applied to phenolic compounds with the CUPRAC assay," Molecules, vol. 12, no. 7, pp. 1496-1547, 2007. 


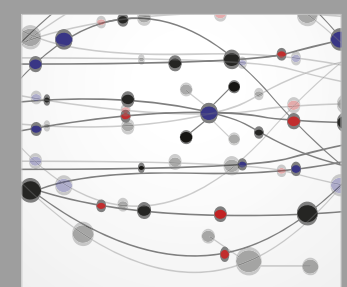

The Scientific World Journal
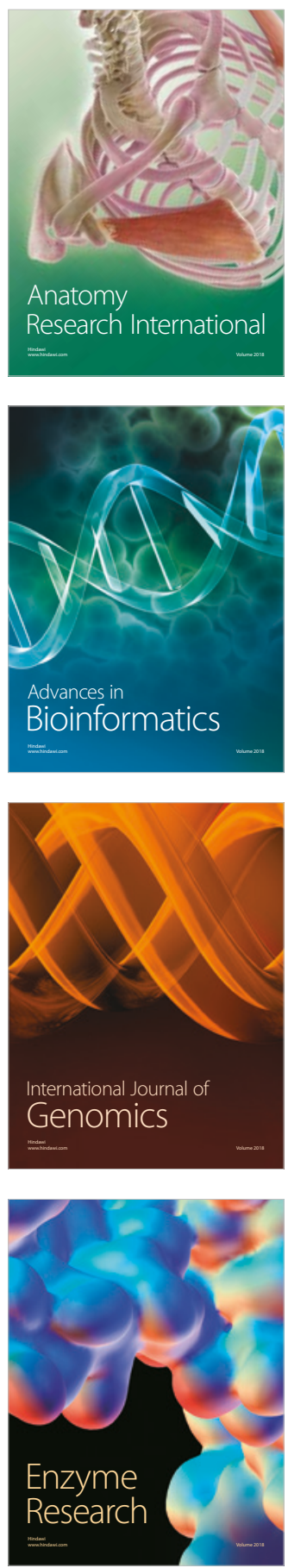
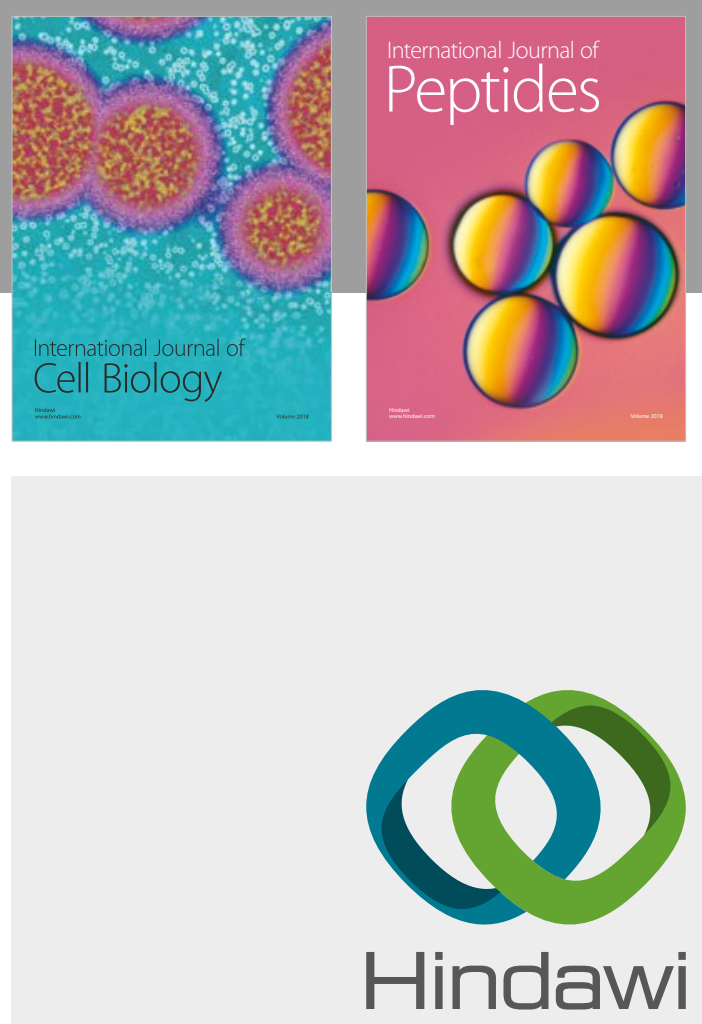

Submit your manuscripts at

www.hindawi.com
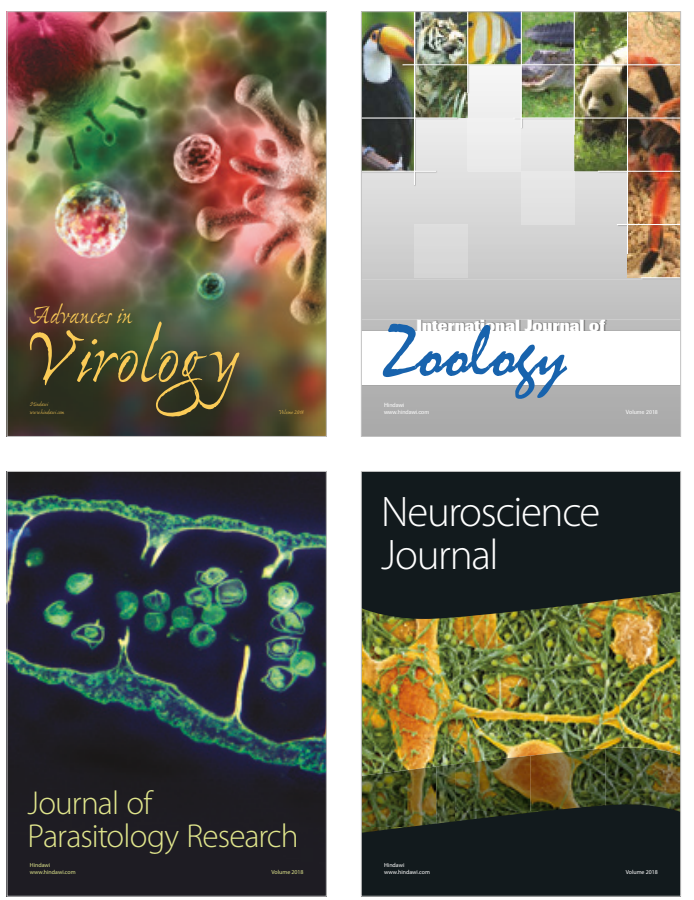
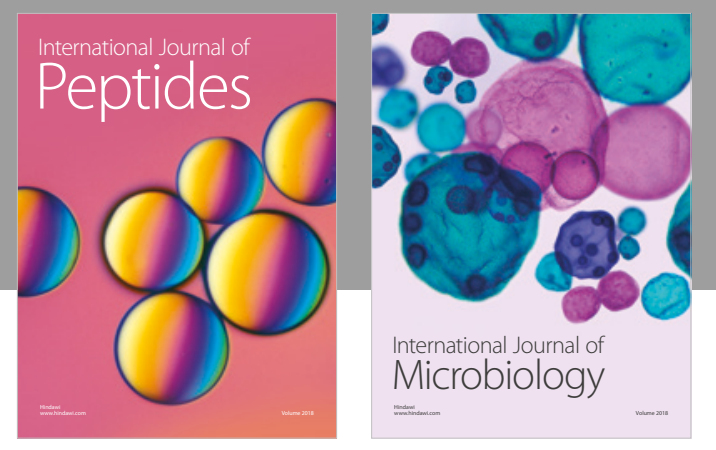

nternational Journal of Microbiology
Journal of
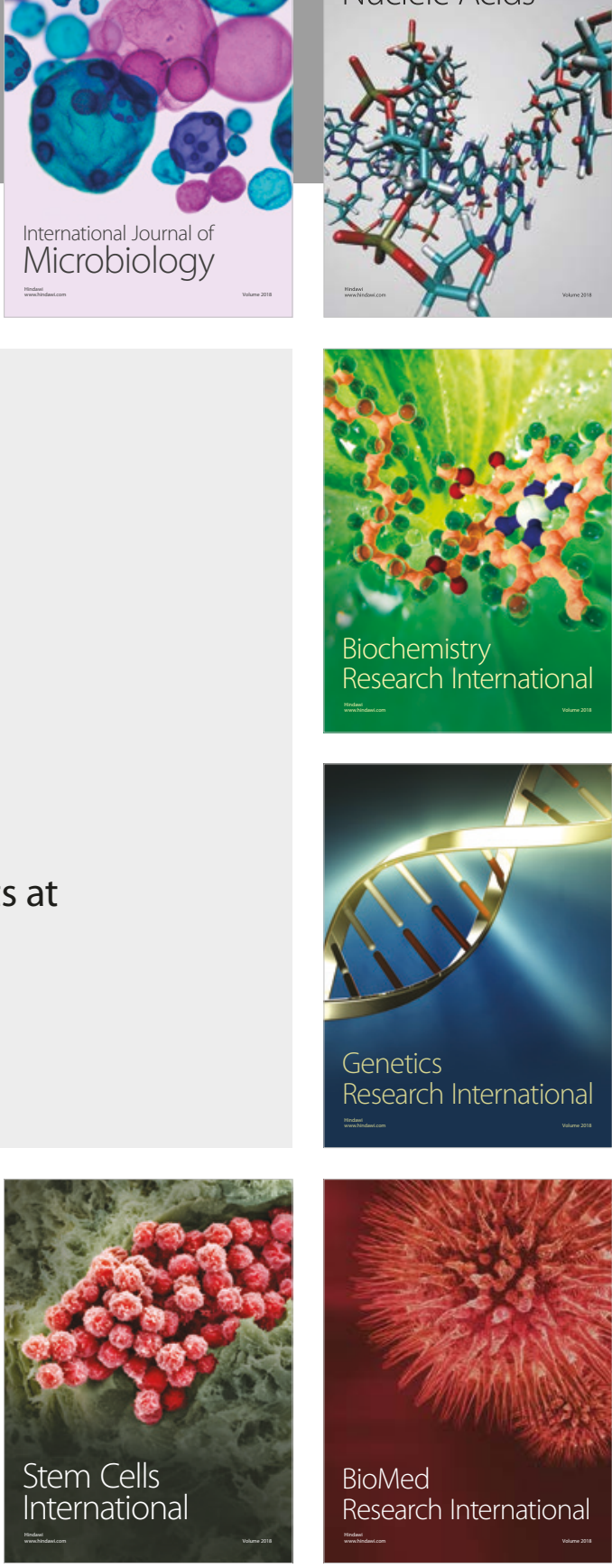
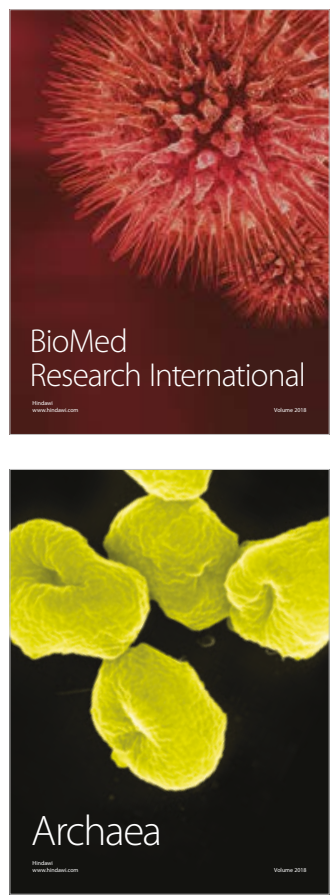